Georgia State University

ScholarWorks @ Georgia State University

Counseling and Psychological Services Faculty Department of Counseling and Psychological

Publications

Services

2016

\title{
Forbidden Identities: A Qualitative Examination of Racial Identity Invalidation for Black/White Biracial Individuals
}

\author{
Marisa Franco \\ Georgia State University, mfranco@gsu.edu \\ Rahel Katz \\ University of Maryland at College Park, rkatz27@umd.edu \\ Karen M. O'Brien \\ University of Maryland at College Park, kmobrien@umd.edu
}

Follow this and additional works at: https://scholarworks.gsu.edu/cps_facpub

Part of the Counseling Psychology Commons

\section{Recommended Citation}

Franco, Marisa; Katz, Rahel; and O'Brien, Karen M., "Forbidden Identities: A Qualitative Examination of Racial Identity Invalidation for Black/White Biracial Individuals" (2016). Counseling and Psychological Services Faculty Publications. 4.

https://scholarworks.gsu.edu/cps_facpub/4

This Article is brought to you for free and open access by the Department of Counseling and Psychological Services at ScholarWorks @ Georgia State University. It has been accepted for inclusion in Counseling and Psychological Services Faculty Publications by an authorized administrator of ScholarWorks @ Georgia State University. For more information, please contact scholarworks@gsu.edu. 
Forbidden Identities: A Qualitative Examination of Racial Identity Invalidation for Black/White Biracial Individuals 


\begin{abstract}
This qualitative study examined instances of racial identity invalidation among 49 Black/White Biracial individuals. Transcriptions of participants discussing their most stressful experience of invalidation were coded for themes using content analysis. Themes that emerged provided a rich description of Biracial participants' perceptions of why invalidation occurs and why perpetrators invalidated the individual. Also addressed are Biracial people's thoughts, feelings, and reactions in response to the invalidation, and the effect of the invalidating experience on racial identity. Implications for research and preventive interventions are provided.
\end{abstract}

Keywords: Biracial; Multiracial; Racial Identity Invalidation; Racial Identity 


\section{Introduction}

Racial identity invalidation is one of the most stressful racial experiences that Biracial individuals face (Rockquemore \& Brunsma, 2004; Shih \& Sanchez, 2005; Townsend, Markus, \& Bergsieker, 2009). This stressor occurs when an individual is placed into a racial category that does not align with the racial category with which they personally identify (Lou, Lalonde, \& Wilson, 2011; Rockquemore \& Brunsma, 2004). Identity invalidation can take the form of accusations of racial inauthenticity, imposition of racial categories, and forced choice dilemmas (Buckley \& Carter, 2004; Gillem \& Thompson, 2004; Rockquemore \& Brunsma, 2002).

Research has shown that invalidation has a number of negative effects. It decreases self-esteem, promotes negative affect and resentment towards the perpetrator of invalidation, inhibits racial identity development, and contributes to negative mental health outcomes (Rockquemore, 2002; Rockquemore \& Brunsma, 2002; Townsend et al., 2009). For this stressor to be understood, so that it can be dismantled, the characteristics of racially invalidating experiences must be studied from the perspective of Biracial individuals. Thus, the purpose of the current study is to advance knowledge regarding experiences of identity invalidation in the lives of Black/White Biracial individuals.

Self-verification theory provides a suitable theoretical lens from which to examine racially invalidating experiences as it highlights the importance of alignment between others' perceptions of the self and self-perceptions (Swann, 2012; Swann \& Bosson, 2010). The desire for self-verification is fueled by wanting to view social reality as coherent and predictable; a sense of control arises in navigating the environment when external responses can be predicted accurately. Agency also results when one is able to use self-perception to guide behavior and inform social realities (Swann \& Bosson, 2010). 
The construct of interest in this study, racial identity invalidation, can be understood as an undermining of self-verification within the domain of racial identity. In other words, when identity invalidation occurs, others refute one's understanding of one's racial identity. Identity invalidation can have negative consequences for two strata of identity: self-identity and group identity (Lou et al., 2011; Swann \& Bosson, 2010). When others impose a race that is disharmonious with self-identity, it can call into question or even diminish perceptions of one's racial identity. Moreover, identity invalidation by in-group members threatens belonging by undercutting acceptance and possibly leading to disenfranchisement from one's social group.

Invalidation is so pivotal to the identity development process of Biracial individuals that several frameworks of Biracial identity incorporate identity invalidation (Edwards, 2008; Rockquemore \& Brunsma; 2002; Rockquemore \& Laszloffy, 2003). For example, in conceptualizing different ways that Biracial people identity, Rockquemore and Brusma (2001) separate an exclusively Biracial identity, of which they call a "border" identity, into two types: unvalidated, and validated. Similarly, a number of Biracial researchers have emphasized the importance of differentiating between an "ascribed" and an "internal" identity in conceptualizing Biracial identity (Edwards, 2008; Rockquemore, Brunsma, \& Delgado, 2009). Indeed, research has found that Biracial individuals who share the same identity may experience disparate psychological outcomes depending on their degree of identity validation (Coleman \& Carter, 2007; Lou, Lalonde, \& Wilson, 2011). The Multidimensional Model of Racial Identity proposes that experiences of invalidation may be more important than identity choice in influencing psychological outcomes for Biracial people (Rockquemore \& Brusnma, 2001). In addition to influencing psychological health, theorists have posited that repeated experiences of being “corrected" about one's identity affects racial identity choice (Brunsma \& Rockquemore, 2001; 
Harris \& Sim, 2002).

Biracial individuals are particularly at risk for identity invalidation because historically, race has been grounded in a monoracist system in which Biracial individuals have been coerced into identifying with their minority identity, in part to preserve the existing racial system (Gillem \& Thompson, 2004; Shih \& Sanchez, 2005). While some Biracial individuals may identify as Biracial, others define themselves as belonging to a monoracial category. Despite either mode of identification, Biracial individuals experience identity invalidation. For example, Biracial individuals who might identify as Black may find their racial authenticity and identity called into question (Rockquemore \& Brunsma, 2002; Tashiro, 2002; Romo, 2011). Furthermore, Biracial people may have an ambiguous identity that prompts people to question their identity by asking “what are you?" (Miville, Constantine, Baysden, \& So-Lloyd, 2005); this experience may be internalized as an invalidation of identity (Remedios \& Chasteen, 2013).

Identity invalidation may be particularly salient for Black/White Biracial individuals. Categorization research indicates that Black Biracial individuals are highly vulnerable to invalidation, especially an imposed Black identity. A study by Herman (2010) found that part Black-Biracial people were more likely to be categorized by their minority identity than part Asian, Hispanic, and Native American Biracial people. Similarly, across five studies, Ho et al. (2010) found that hypodescent labels were more prevalent for part-Black than part-Asian individuals (Ho et al., 2010). This research, in light of the historical dynamics within America, make the Black/White Biracial population an important demographic to investigate in relation to invalidating experiences.

This research is important because experiences of identity invalidation can have deleterious effects on mental health and racial identity. Identity invalidation has been found to 
relate to low self-esteem, decreased motivation, anxiety, and depression (Coleman \& Carter, 2007; Lou et al, 2011; Sanchez, 2010; Townsend et al., 2009). Moreover, invalidating experiences have led Biracial people to feel that they could not choose their racial identity freely, that others perceived the Biracial group negatively, and that their component racial groups were not harmonious (Lou et al., 2011; Sanchez, 2010). Moreover, identity invalidation has been thought to hinder healthy identity development (Buckley \& Carter, 2004; Khanna, 2004; Rockquemore \& Brunsma, 2002; Tashiro, 2002) and often arises as a unique and vulnerable form of stress in Biracial people's discussions of their experiences of discrimination (Harris \& Khanna, 2010; Miville et al., 2005).

To date, we know little about the actual experiences of identity invalidation faced by Biracial individuals. Two notable exceptions provided a general overview of some of the effects of invalidation and its relationship to racial identity. Specifically, Rockquemore and Brunsma (2002) created a categorization system for Biracial identities, and examined how invalidation interacted with these identities. In this study, individuals who were validated as Biracial were more likely to be part of White social networks than Black ones. Similarly, Romo (2011) examined accusations of racial inauthenticity among Black-Mexicans. Biracial participants were invalidated in attempting to identify as Biracial or as Monoracial. The latter type of invalidation occurred because their behavior or appearance did not align with perceived markers of racial authenticity.

The current study will contribute to the existing literature by providing an in depth, rich description of instances of identity invalidation experienced by Black/White Biracial individuals and their direct reactions to these experiences. This focused approach to examining invalidation will provide a nuanced understanding of how identity invalidation manifests in the lives of 
Black/White Biracial people that can be used to develop interventions to ameliorate negative mental health outcomes resulting from invalidation.

\section{Method}

\subsection{Participants}

Forty-nine participants were included in the present study. Participants ranged from ages 18 to $41(\mathrm{M}=22.12 ; \mathrm{SD}=4.53)$. A majority $(69 \%)$ of participants were female, and the remainder were male. Most participants were students (86\%) and all lived in the Washington, DC metropolitan area. Most $(90 \%)$ were heterosexual. In terms of racial composition of parents: $16 \%$ of participants had a Black mother, $63 \%$ had a Black father, $57 \%$ had a White mother, $27 \%$ had a White father, 27\% had a Biracial mother, while $8 \%$ had a Biracial father. Regarding education, $14.2 \%$ had completed some high school, $53.1 \%$ had completed some college, $4.1 \%$ had completed an associates degree, $20.4 \%$ had completed a bachelors degree, and $8.2 \%$ had completed a masters degree. In regards to income, $28.6 \%$ were below $\$ 49,999,30.6 \%$ between $\$ 50,000$ and $\$ 99,999,18.4 \%$ between $\$ 100,000$ and $\$ 149,999,12.2 \%$ between $\$ 150,000$ and $\$ 199,999$ and $10.2 \%$ above $\$ 200,000$. A majority (85.7\%) identified as Biracial, while the rest $(14.3 \%)$ identified as Black.

\subsection{Procedure}

2.2.1. Recruitment. Participants were recruited for a larger study examining the effects of race-related stress on cardiovascular reactivity for Black/White Biracial people through advertisements on online groups catering to Biracial individuals, email messages to personal contacts and research team member connections, email messages sent to a list of Biracial individuals obtained from the registrar of a large mid-eastern university, fliers distributed on the campus of this university, and personal invitations to Biracial student organization members at 
the university. Recruitment materials read, "Do you have one Black parent and one White parent?" and avoided terms such as "Multiracial" and "Biracial" so individuals who did not identify as such would not be omitted. Additionally, after participating in the study participants were asked to distribute fliers to people they believed might be eligible and interested. Participants received ten dollars or extra credit in psychology courses for their involvement in this study.

2.2.2. Study Design. In the original study, participants came into a laboratory to discuss experiences of race related stress while their blood pressure was taken. As part of the study, participants were prompted by a computer to discuss, in a counterbalanced manner, experiences of racial identity invalidation, discrimination from family, and engaging in a leisurely activity. The prompt related to racial identity invalidation was as follows:

Talk about the most stressful experience you have had where others have attempted to impose a racial group upon you that you do not identify with and/or have invalidated or denied the way that you racially identify yourself. To help you talk about the experience, you may want to consider the following questions: 1) What are some of the details of the experience? Who tried to impose a racial group onto you, or invalidated your racial group membership(s)? What did the person say or do to impose a racial group on you or invalidate your racial group membership(s)? What might the intentions have been of the person who tried to impose a racial group onto you, or invalidated your racial group membership(s)? 2) How did this experience make you feel? 3) What were the thoughts you had before, during, and after this act of invalidation happened? 4) How did this event affect how you perceive yourself? 
Please continue to talk about and experience this event and your reactions to it for the next four minutes. Your response will be recorded through a video camera.

Their responses were recorded on video and transcribed by a research assistant, verbatim, excluding minimal phrases, such as "umm." Transcripts were checked by a second research assistant for accuracy, and were discussed with the primary investigator whenever the transcripts were unclear.

2.2.3. Manipulation Check. The first and last authors watched videos of participants discussing their experiences of racial identity invalidation, discrimination from family, or engaging in a leisurely activity. They blindly rated all videos on the degree to which participants discussed racial invalidation, discrimination from family, engaging in a leisurely activity, or a grading dispute. The racial invalidation videos were extracted from the larger pool of videos for the present study. The following manipulation check item addressed racial invalidation: to what degree did the participant talk about an experience where others have denied the way in which they racially identify themselves on a scale from 1 (not at all) to 4 (completely)? Agreement between raters for this item was high $(\mathrm{ICC}=.90, p<.001,95 \% \mathrm{CI}[.84, .92])$. Videos rated differently by each rater were re-watched and discussed until a consensus score was reached. Videos with ratings of 3 or 4 were included in the final analysis. From the original 60 participants, a subsample of 49 achieved high enough ratings to be included in the analysis.

\subsection{Analysis}

2.3.1. Researchers. The original research team consisted of a female Black/White Biracial doctoral student in psychology, a post-bachelors Asian male, a Black female undergraduate, and a White Jewish female undergraduate. About halfway through transcript coding, the Black female and Asian male were replaced by two Black female undergraduates. 
During the coding meetings, each member would present a transcript and their codes, while other members gave input pertaining to the coding decisions, and presenters were rotated. Throughout the study, the researchers discussed their reactions to the data.

Content analysis (Roberts, 2001) was used to code the transcripts. First, two members of the research team read the transcripts multiple times and independently generated themes. They then collaborated in compiling a list of overlapping themes and subthemes. Once an initial set of themes were created, two additional research assistants independently applied themes to all transcripts. The researchers met regularly to discuss the themes, and collaborated to achieve consensus around coding discrepancies. The themes were revised throughout the study to best fit the data. Once the analysis was completed, four researchers read through all themes, once more, to assess whether information was coded accurately.

The auditor, a White female professor of psychology, provided feedback about the themes and subthemes twice during the interpretation process (once in the middle, and once at the end). The four research team members reviewed the auditor's comments and themes were adjusted or data were moved to respond to the feedback.

\section{Results}

3.1. Racial invalidation demographics. The most common settings where identity racial invalidation occurred included at school, while spending time with friends, and while filling out a standardized form. Racial identity invalidation that occurred at school or school-related events made up almost half (45\%) of the described instances. Of these, 33\% occurred in elementary or middle school, 33\% in high school, and 27\% in college. Most of the participants reported that the racial composition of the setting where the invalidation occurred was predominately White 
(73\%); some reported that it was predominately Black (27\%). The perpetrators of invalidation were Black (38\%), unspecified in race $(29 \%)$, neither Black nor White $(21 \%)$, or White (12\%).

Racial invalidation also was coded based on type. In some instances of invalidation, the Biracial person's self-identity was negated (e.g., you're not really a Black person), while in other instances, an identity was imposed onto the Biracial person (e.g., you should identify as Black). In total, 23 instances of identity negation were reported; out of these, $74 \%$ involved a negated Black identity (e.g., you're not really Black), 17\% involved a negated White identity, and 9\% involved a negated Biracial identity. There were 32 instances in which an identity was imposed onto the Biracial person: of these, $44 \%$ involved an imposed Black identity, $44 \%$ an imposed White identity, 9\% imposed some other identity, and 3\% involved an imposed Biracial identity.

The following sections describe the main themes (endorsed by at least 5 participants) that emerged from the content analysis. For each theme, the percentage of participants who reported the theme is indicated. For a complete list of themes, see Table 1.

\subsection{Reasons for Racial Invalidation}

Twenty nine (59\%) participants reported on their perceptions of the triggers for the racial identity invalidation; specifically, racial identity invalidation occurred when phenotype did not match racial identity, when behaviors did not match racial stereotypes, and when ancestral heritage did not match personal racial identity.

3.2.1. Phenotype. Sixteen participants ( $33 \%$ of the sample) described instances of invalidation that occurred because their appearance did not match a racial prototype. Racial invalidation grounded in phenotype was sometimes unintentional on the part of the perpetrators. They made automatic assumptions that conflated appearance and racial identity. Other times, perpetrators intentionally disregarded a Biracial person's personal identification, arguing that 
their appearance was more revealing of their race then any personal proclamation. Having people misperceive them caused some of the participants to be excluded from racial groups. For example, one participant discussed being recruited by mail by the Black Student Union, until members of the union witnessed her appearance:

The Black student's association tried all summer to get me interested in them, and when they saw me, they pretty much decided that I was not what they were looking for..._I had never experienced anything really like that before, where someone didn't accept me because of the way I looked and how I compared to them.

Another participant described being perceived as White, and thus being exposed to racist beliefs:

I think that in general people kind of unconsciously impose the White racial group on me, just kind of assuming. So occasionally people will say insensitive or just outright bigoted or racist things, or things that I know they would not say if there were a person with darker skin in the room... [A co-worker] was talking about the preference that's given to Black architects in terms of getting contracts and how it's unfair or it doesn't represent/result in the best architect being hired. In a way, I know he wouldn't have done that if there was somebody Black in the room.

Some participants described others being confused about their race because of their appearance. This confusion sometimes led to a categorization as Hispanic. For example, one participant divulged:

Before I always kind of had this thing where people didn't perceive me as Black or perceive me as just White. Even sometimes people would perceive me as Hispanic. I remember being in the line at the diner and some guy saying "You're Dominican right?" 
3.2.2. Racial stereotypes. Fifteen participants (31\%) described invalidating experiences that occurred because their behaviors did not fit with racial stereotypes. Of these, $87 \%$ discussed having their Black identity negated, i.e., they were told they were not Black enough. For example, one participant discussed being critiqued by her classmate because of her behaviors:

One of the guys in my class came up to me and told me that I'm not Black enough. I'm too White, talked too White, dressed too White, acted too White, and that basically I need to be more Black.

Another participant discussed being called the derogatory term "oreo" because her behaviors did match those prescribed to Black people:

The term "oreo" started being brought for like White people who act Black or Black people who act White. And of course I was identified, growing up in a predominantly White school, as being an 'uh-oh Oreo,' a Black person who acted White... 'You act like this way. You're not really Black"... It would later be brought up by a guy named [C]. He was also Black. It always turned back to [him saying] I was rejecting my race by not acting the way I guess I was supposed to... by not dating Black guys, I was rejecting part of myself.

3.3.3. Grounded in ancestry. A less common reason for invalidation, reported by five participants (10\%), occurred because their ancestry did not match their racial identity. In these experiences, participants reported being forced to identify with both of their heritages by others, or else not being allowed to identify with a Monoracial group, because of others knowledge of their mixed racial heritage. For example, one participant stated:

[A friend and I] were talking about President Obama and she said, "Well you know he's not a Black president. He's half Black and he's half White, and I think it is disrespectful 
to his White side that he identifies himself as Black"... She kept telling me how disrespectful it was to my White, quote-unquote, my White race that I don't identify. Two participants discussed not being allowed to identify as Black because of others knowledge of their White ancestry. For example, one participant discussed angering other Black students after being invited to receive an award granted only to Black students.

After [I received the award], nobody came up directly and said anything but it was talked about around the school because people were mad that I got invited to do it because I'm only mixed and not fully Black. It was mostly my Black peers who were angry about it, which is kind of obvious because that's what the program is for. They didn't say anything to me personally but a lot of my friends said that in their classes, they had discussions about it and people were getting a little stirred up about it. I think the people who were mad about it were just kind of upset because I guess people have different views of what race or ethnicity a person is...depending on like percentages and stuff like that.

\subsection{Reasons for Perpetrator Invalidating}

Participants discussed having certain characteristics_-behaviors, appearance, ancestry_that made them more vulnerable to being targets of invalidation, while they also revealed perpetrator's motivations for invalidating another's racial identity. From the perspective of 20 participants (41\%) who addressed reasons why others might have invalidated their identity, the most common reasons why perpetrators invalidated was because they had essentialist views on race, because they felt the need to correct the Biracial participants racial beliefs, to build their status, or to be humorous.

3.4.1. Essentialist views on race. Nine participants (18\%) indicated that they were invalidated because others had essentialist views on race, believing that racial groups are 
separate and distinct and that each group has a certain homogenous set of attributes. Perspectives related to the one-drop rule (i.e., any Black ancestry necessitates a Black identity) were placed within this category, For example, one student discussed an interaction with the Black student union, where others thought that Black was the only acceptable way for a Black Biracial person to identify:

The thought... of those individuals was that I was somehow denying my Blackness by identifying myself as mixed race...I didn't join a lot of things like [the Black Student Union], but basically when I did not want to, it showed that I identify myself as being mixed as opposed to only Black. There was some animosity that arose from that, and I felt as though they perceived me as somehow having an issue with the fact that I that I was partially Black, or [because I] didn't identify myself solely as Black then somehow, I'm looking down upon my Blackness.

Another participant discussed their experience on a Black student retreat, and being faced with a homogenous set of criteria on what being Black should look like:

The Black student retreat, so I decided to go on it, but I ended up feeling really frustrated by it...this sort of model or image of what it means to be Black... and I felt like I didn't fit that, and I felt that no one was open to talking the diversity within Black people - that we're not all the same exact person. Other people said other things that fed off on that energy: we need to stick together, and that sort of thing.

Perpetrators who invalidated because of an essentialist view on race seemed to make a set of assumptions based on part Black ancestry, one of which was that part Black ancestry necessitates a Black identity, or else that part Black ancestry should specify a predetermined set of behavioral characteristics. For example, one participant told of a time when a young boy was 
confused because he thought that the participant's manner of speaking was not consistent with being Black:

Still, the kid was kind of confused. He was a bit younger than me. He said, well, how can you be Black and sound White? Like, he just didn't accept that this could be possible, or he just didn't accept the fact that I was Black. He just saw me, kind of as a White person. 3.4.2. Setting someone right. Six participants $(12 \%)$ reported that perpetrators invalidated them because they felt the need to teach them how they should identify. Of these, $67 \%$ indicated that they were told that they must identify as Black. The perpetrators instructed participants on how society might see them, and demanded that they identify accordingly. For example, one participant described being told that he should identify as Black:

The individual that I'm thinking about, his name was (V). He felt that somehow he needed to help me understand that because I am perceived as Black, I need to embrace it, and that's what I need to be, and I don't need to identify as anything else, or that somehow, saying that I'm mixed like I said makes me ashamed of being Black or I'm trying to be better than others by stating that status.

3.4.3. Status building or personal gain. Six participants (12\%) indicated that perpetrators invalidated their racial identity to fulfill a personal agenda (e.g., build their status or meet a personal goal). For example, one participant indicated that her invalidation allowed her perpetrator to escape invalidating accusations:

From her point of view, I think [she] really could feel superior by [acting Black]. I don't know if her intention was to bring me down... [and] kind of reaffirm herself as being the quintessential Black person... and here's this faker over here who has turned....against it. 
Another participant discussed how her friends were motivated to impose a Black identity on her as a way of elevating the social status of their friend group:

I'm thinking that they think differently of me because I'm the token Black girl among my White peers...like I was a prize or something that they had earned friendship with, or I added some weird thing to their group that not many of the groups at my school had.

3.4.4. Humor. Five participants $(10 \%)$ indicated that perpetrators invalidated in an attempt to be humorous. In some instances, participants did not feel that the invalidation was malicious and were less likely to become upset with invalidators. For example, one participant discussed a conversation she had with her boss:

He said "You're not Irish"...he's like "No, you're just Black." ... Then he said "No, you don't even talk to the White side of your family, so you're Black: you dress Black, you act Black, you're just Black with light skin like a White person”...He just said that I associated more with the Black side than I do with the White side of me...He didn't have any bad intentions, I don't think. He was just joking around... I don't think he tried to [and he] didn't make me feel bad.

Another participant discussed an interaction with his friends:

I don't remember what was going on really, but I remember one of [my friends] saying, "[T] shut up you're not Black"...so what the intention was [to make] a joke, I guess he was just trying to be funny at the time ... We do joke a lot.

\subsection{Direct Behaviors in Response to Racial Invalidation}

Following the racial invalidation, eighteen (37\%) participants responded in one of two ways: either more proactively, addressing the invalidation and voicing active disagreement, or by accepting the invalidation without protest. 
3.5.1. Resistance: Spoken disagreement. Eleven participants $(22 \%)$ actively disagreed with the invalidator. When these participants had a monoracial identity negated or imposed, they fought back by questioning racial stereotypes about what it means to be a member of a certain group. For example, after being accused of being "white-washed" by a roommate because of her behaviors, one participant responded by deconstructing the use of stereotypical behaviors to define racial group membership:

And I told her that it offended me because I don't consider myself one race over the other. But usually I will just say to them, "My dad is Black but he is more educated than my mom who's White so it's kind of invalid what you're saying"....or, I just say, "I'm Biracial like my race has nothing to do with the way I act....but it's more of the environment."

When invalidation occurred because perpetrators did not accept a Biracial identity and felt the need to view participants monoracially, they responded by citing their ancestry, or the racial composition of their parents, as a valid reason to support their identity choice. For example, after a participant checked two races on a demographic form, a peer indicated that they should be identified as Black because of the one-drop rule and because others perceive them as such. The participant responded:

I was [like] "No_-I'm half Black half White. I have one parent that's Black and one parent that's White." I'm like "No, that's not true, just because my skin says [that I'm Black]"... I just felt the need to uphold my beliefs or uphold... the group I identify myself with.

3.5.2. Deflecting. Eight participants (16\%) responded to the invalidation with little protest. Participants did not address the invalidation because they supposed that a potential 
response to the invalidation would be unsuccessful, did not know how to respond effectively in the moment, or felt that addressing the invalidation might lead to negative consequences. For example, one participant who is exposed to a racist remark because a coworker was not aware of his racial background, discussed how addressing the invalidation would be ineffectual:

This guy is very senior to me so I kind of just smile and nod. I don't pick that fight. As I'm saying this, do I feel guilty about that? Do I think I have a responsibility to push back on that and make that point? And I don't... I don't you really feel guilty because, I don't think that it would be possible to have an honest conversation about that, where we end up making any kind of progress. What could I say? Rip off the metaphorical mask and say “Ahh ha, I'm partly Black, what do you think about this now?" That's just a very combative way to get into that kind of conversation.

\subsection{Thoughts Following Racial Invalidation}

After experiencing the racial invalidation, 21 (43\%) participants reflected on the validity of the comments and mostly disagreed. Invalidating experiences also led participants to reflect on the construct of race or to reflect on how others around them construct race, and particularly, determine the race of the participant.

3.6.1. Internal disagreement with invalidator. Following the invalidation, fourteen participants (29\%) thought about how they disagreed with the invalidator. In doing so, they cited reasons to discredit the invalidator's argument for them to identify in a particular way, and also thought about reasons why their choice of identity was valid. For instance, after a participant was told that she was not Black or African enough because of her skin color, one participant thought about the phenotypic diversity of African people to indicate that gradients of skin color cannot be used to invalidate someone's Black or African identity: 
A lot of people in the African continent, we all come in different shades and colors. Just because I was mixed, my shade was a little is lighter, but there's other people that are from Africa that do not have any type of mixing that you know have been both African Americans that are much lighter than me.

Another participant disagreed with being called the "token Black girl" by her friends, and thinks about her own perspective on her identity. She refers to her family racial composition in supporting her decision to identify as Biracial:

[There] is nothing wrong with being the Black girl because most of the time I am the Black girl but, I just [think] they were denying this entire other part of me. I'm like, why are they doing that? Don't they see that I have a White mom? I'm not just the Black girl, and I have a Black dad. I'm not just the Black girl. I accept both sides of my race...Then after they would say it, I would be thinking how stupid that is. Why are you trying to categorize me and not just letting me be who I am?

\subsubsection{Reflections on how others construct race and perceive participant's race. After}

the invalidation, 11 participants $(22 \%)$ reflected on how others perceive their race, and/or how others understand race generally. Some participants evaluated their invalidating experiences in light of larger racial dynamics in America. After having a White identity imposed, another participant deconstructed how others wrongfully understand race through racial stereotypes:

I view race as more of a social construct. I understand when my White friends or my Black friends say I am more than another because they're just referring to the way I grew up. But, I also view it in an offensive way. Just because I'm smart or an educated person and I don't speak slang, they're viewing [me] more as White and they're associating 
well-spoken or well composed and being more educated with being White rather than being Black and viewing Black people as less educated and [being] ghetto.

After having a White identity imposed on her because of her appearance, another participant used her invalidating experience to inform her feelings of confusion related to how she is perceived, racially, by others:

I am cognizant of the fact that, Black people don't see me as Black, and White people see me as White. So, when people first meet me, they don't understand my background. So I guess it kind of brought to light that not everybody understands my situation.

3.6.3. Reflections on construct of race. Nine participants (18\%) thought about the broader construct of race, following the invalidation. These participants pondered about the meaning of race, and the position of certain racial groups, within society. They used their invalidation as a funnel through which to understand the broader concept of race. For instance, after a participant was told by a Black male that her phenotype precluded her from being allowed to have a Black identity, a participant reflected:

I just really wondered and pondered what the difference was between me and him. I'm mixed. I don't see myself as either Black or White. I see myself mostly as a person, but when he asked me [what race I was, I said] "oh I'm mixed.” It's just who I am...I just keep realizing what the struggle is for a mixed person. ..who can't [be seen] see as just one race...[other people] thinking they can understand being Biracial.

Another participant was told that by a White female peer that she did not see him as Black, and he used this experience to inform his perception of the construct of race in America: 
On the one hand, I think [there] is a lot of progress in how people see race in America. I mean, the whole one-drop rule we have is kind of ridiculous in many ways. I thought that was in some ways a sign of progress.

\subsection{Feelings in Response to Racial Invalidation}

Thirty-four (69\%) participants mentioned a variety of different feelings in response to the invalidation, with the most common feelings being upset or hurt, confused, excluded or isolated. Many participants reported multiple feelings in response to the invalidation.

3.7.1. Upset or hurt. Sixteen participants (33\%) discussed feeling upset or hurt in response to the invalidation. One participant discussed her reaction to being accused of not acting Black enough, and told that she needed to change herself to be more align with the behaviors of Black people: "[It] really hurt me. [I] kind of took it to heart...The experience of someone telling me that everything about me was wrong really hurt... It made me feel, I don't know, just bad-horrible.” Another participant discussed her feelings in reaction to being excluded from Black Student Association because she felt that her phenotype didn't qualify her as Black enough to join: "It really bothered me. It was awful. I felt like crap. I just took a huge hit to my self-esteem. It kind of broke me. I called me my mom, I was crying... I just felt horrible."

3.7.2. Confused. Ten participants $(20 \%)$ discussed being confused as a result of the invalidation. They were confused about the invalidator's actions as they thought these opinions on their race did not make sense, or they became confused regarding their identity and sense of self. Participants reported feeling confused about who they are, as a result of the invalidation. For example, one participant was told by a White Jewish peer that she was not Jewish, despite identifying as such, and started to feel confused about her identity after this occurred: "It gives 
me a really confused [feeling] because when all outside forces are telling you one thing then you yourself believe a different thing. It's very conflicting." Another participant discussed being confused about herself after being rejected by the Black community at her school because of her mixed race ancestry: “I guess that's the first time I really felt like I didn't know how I identified myself...the first time I was faced with the question of how do I identify myself."

3.7.3. Isolated. Ten (20\%) participants indicated that they felt isolated as a result of the invalidation, as if they had no racial community for which to belong. Participants perceived themselves as unwanted outsiders. Of these, most (80\%) mentioned feeling excluded after being rejected by a member of the Black community, in particular. This may be because, as a result of the one-drop rule, the Black community is the perceived default community for Biracial individuals. A participant discussed hearing her Black peers forwarding a certain image of what it means to be Black at a Black student retreat and her subsequent feeling that she did not fit in: “And I felt like I didn't fit that [image]. It feels lonely, because even if you try to explain that to someone, there's no one who would get that at all." Another participant discussed his reaction to being told that he didn't count as a Black person:

[It] made me feel lonely I guess. It made me feel like no matter who was going to talk to me, they were going to say I was a part of another group than where I believe I belonged, and after, that's when I felt pretty lonely. I felt like, well everybody is just going to deny where I belong.

3.7.4. Other feelings. Other feelings that participants reported in reaction to the experience of invalidation include feeling shocked, (14\%), uncomfortable (12\%), annoyed or frustrated (12\%), angry (12\%), and offended (10\%),

\subsection{Effects of Racial Invalidation on Identity}


Fourteen $(29 \%)$ participants discussed the effects of the invalidation on their racial identity. Some participants reported that the experience of invalidation did not affect how they racially identified, while others indicated that it had.

3.8.1. No shift in identity. Eight participants (16\%) indicated that the invalidation had no effect on their racial identification because they already had developed a strong sense of self. For some, it seemed that keeping the same identity felt like an act of defiance against the perpetrator. One participant indicated that he was pressured to identify as Black on a form, and indicated that, regardless of this experience, he continued to identify himself as Biracial:

How I identify myself as when I fill out those forms - I put either Biracial or two or more races if not other. I do not simply put Black, I do not simply put White. I am neither of those. I am both. I'm not either. I'm not one or the other. I am both of them. . I identify myself as both, and after it happened I guess I didn't really affect the way that I looked at myself. I still consider myself you know 50 percent Black 50 percent White. That's just who I am, genetically, what I am made of, and that's also who I identify myself with because I had a White parent that raised me and a Black parent that raised me.

Another participant discussed the effects of being told by a peer that she didn't see him as a Black person:

It didn't really affect how I perceived myself. I mean, I had a pretty solid perception of myself and not only of what I thought. This situation made me see myself as not really being able to fit generic racial groups, being Black or White.

3.8.2. Shift in identity. Seven participants (14\%) discussed a shift in their identity as a result of the invalidation. In some instances, participants started to identify in a way that better aligned with perpetrator's perceptions. For example, a participant who was told that she can only 
check one race on a demographic form, and that this race should be Black stated: "I think for the longest time, it made me not think about my White side. It made me think that I am Black because that's how people perceive me and people [are] telling me how I should be." Other participants discussed more strongly identifying as Biracial as a way of escaping having to adhere to racist stereotypes. For example, one participant was told by Black peers that she must shoplift to be an authentic Black person.

This definitely had an effect on how I perceived myself because I didn't want to have an identity with one or the other. I just kind of wanted to have both because that's what I am and who I am... and like the group that I feel like I am like a part of both, just because I'm not full Black.

\subsection{Factors that Exacerbate and Mitigate Racial Invalidation}

In discussing invalidation, twenty (40\%) participants referenced factors that made the invalidation more difficult to manage, or else made it easier. Factors that exacerbated and mitigated invalidating experiences can be used to inform interventions seeking to identify factors that contribute to the harmfulness of invalidation, or to alleviate the harmful effects of invalidation.

3.9.1. Factors that exacerbate invalidation. Ten people (10\%) mentioned factors that exacerbated their invalidation, with content of exacerbation varying greatly across participants. Overall, the invalidation felt more harmful for participants who felt their identity was particularly important, felt insecure about their identity, felt multiple experiences of invalidation at once, or had their Black identity negated by a person who was Black.

3.9.2. Factors that mitigate invalidation. In total ten participants $(20 \%)$ reported mitigating factors the invalidation. Participants discussed two factors, in particular, that lessened 
the harmfulness of invalidating experiences. Specifically, invalidation was mitigated when participants had a stronger sense of self. For example, one participant had her Black identity negated, but she stated that it did not affect her because she was comfortable with herself: "I never felt that my race has ever really been invalidated because I feel pretty comfortable in my skin and I don't really feel that I associate with one race more than the other." Invalidation was also mitigated when participants had supportive relationships with others who affirmed their racial identity. For instance, one participant was told that he did not "speak Black enough," and felt that he was better equipped to cope with this experience because he had other friends who supported his racial identity:

I mostly identify myself as kids from Africa, or from Europe, who were born and raised, because they had a similar situation to me-or just kids with foreign parents, because it was easier to relate to them than to relate to kids in America... The [invalidators] weren't people I usually hang out with. The people I usually hang out with are usually more accepted of who I was, and they just understood my situation.

\section{Discussion}

The current study focused on elucidating instances of racial identity invalidation and their effects on the lives of Black/White Biracial people. Among our participants, invalidation occurred because others conflated race with certain behaviors or a prototypical phenotype, or because others assumed that racial heritage should match racial identity. Participants perceived that others invalidated them because others had essentialist views on race, felt the need to set someone right, wanted to build their status, or were attempting to be humorous. In response to invalidation, participants resisted the invalidator, or deflected the invalidation by not directly addressing its occurrence. Even when participants did not directly address the invalidation, they 
often thought later about how much they disagreed with the invalidation. The invalidation experience led participants to reflect deeply on the construct of race and on how others construct race and view them, racially. Participants reported a variety of negative experiences in response to the invalidation, most notably being upset, confused, or isolated. As a result of the invalidation, some participants altered their racial identity, while others did not, in part, because they had already developed a strong sense of self. Indeed, a strong sense of self, along with affirming relationships were identified as factors that mitigate the harmfulness of invalidating experiences.

Two of the themes that emerged (i.e., essentialism, and setting someone right) indicated that perpetrators perceived an objective and correct way for Biracial people to identify. This position was endorsed in early models of Biracial identity (Poston, 1990; Stonequist, 1937), while newer theories emphasize the agency of the Biracial person in being able to chose their racial identity (Rockquemore et al., 2009; Shih \& Sanchez, 2009). Indeed, the earlier models perpetuated invalidation by upholding the idea that Biracial people must conform to a certain identity and that deviation from this identity was not acceptable.

Yet to be explored in past research were direct reactions to racial invalidation, uncovered in the present study. In response to racial invalidation experiences, Biracial people deflected, not addressing the invalidation directly, or disagreed, either directly or upon reflection. They also reflected deeply on their understanding of race and how others perceive race. Instances of invalidation informed overall understandings of the construct of race. This process may be somewhat similar to "encounter" experiences_racial experiences that are so jarring that they shake fundamental beliefs about personal identity and the racial system (Cross, 1978). Invalidation may comprise a unique encounter experience for Biracial people that not only shifts personal beliefs about race, but also beliefs about how others understand race. 
The current study identified emotions that invalidating experiences engender such as feeling upset/hurt, confused, and isolated. A number of studies have delineated how identity invalidation may influence mood states: specifically, invalidation may contribute to increased levels of anxiety and depression (Coleman \& Carter, 2007; Lou et al, 2011; Sanchez, 2010). The negative feelings that result from invalidation may play a mediating role in the link between invalidation and negative mental health outcomes.

In line with past research, the current study found that invalidation may engender confusion over identity and sense of self (Lou et al., 2011), and a sense of isolation (Shih \& Sanchez, 2005). A useful concept for framing Biracial people's feelings of isolation is "cultural homelessness," defined as feelings of not belonging to any one group (Navarette \& Jenkins, 2011; Vivero \& Jenkins, 1999). Research indicates that Biracial people experience heightened rates of cultural homelessness (Hoersting and Jenkins, 2011; Vivero \& Jenkins, 1999), and the current research suggests that racial invalidation experiences may be contributing factors to feelings of cultural homelessness. As one participant recounted, regarding their invalidation experience: "[It] made me feel lonely. It made me feel like no matter who was going to talk to me, they were going to say I was a part of another group than where I believe I belonged.”

The current study found some support for experiences of racial invalidation shifting identity. The movement seemed to occur as a way of protecting one's self against future instances of invalidation. For example, some participants altered their identity to be more in line with external perceptions, while others shifted to identify as Biracial to escape monoracial stereotypes. Others reported no change in identity as a result of invalidation; one reason this may have occurred is because this research inquired about identity alteration after one specific instance of invalidation. The cumulative effects of repeated experiences of invalidation may have 
differential effects of identity. Harris and Sim (2004) posited that cumulative instances of being “corrected" about identity may ultimately lead Biracial people to conform with others' expectations of identity.

Findings from the current study underscore the complexity of a Biracial identity. Even when Biracial individuals identified as such, they were still hurt by invalidation related to their Monoracial identities. This may suggest that, for some, a Biracial identity may denote identification with component Monoracial groups as well. Indeed, most Biracial people reported that their most stressful invalidating experience was in relation to a monoracial identity. Specifically, the two most common forms of invalidation were negation of Black identity, and imposition of Black identity or a White identity. This finding is similar to that of Miville et al. (2005) who found that Biracial people identified as simultaneously Biracial and monoracial. Specifically, Miville et al. (2005) suggested that Biracial people may identify as Monoracial to belong to a community, and thus invalidation of monoracial identity may suggest exclusion from that racial community and contribute to feelings of isolation.

The prevalence of both negation and imposition of a Black identity also positions Biracial people in an confusing place in which they are expected to identify with the Black community, but also may be subject to invalidation when they do so. This finding was in line with past research that suggested that Biracial people receive "conditional acceptance" into the Black community (Harris \& Khanna, 2010; Leverette, 2009; Thorton, 2009). Such conditional acceptance may occur because historically, the Black community was the expected home for Biracial people. Currently, a transition period is occurring where Biracial people are still somewhat assumed to identify with the Black community, but are beginning to create a Biracial community of their own (Shih \& Sanchez, 2009). 


\subsection{Limitations}

While a strength of the work is the large number of voices included, each Black/White Biracial person discussed their invalidation experience for only four minutes. Also, participants were given a suggestive prompt via the computer, and were given the option to respond to the prompt or else discuss the invalidation in any other way. This, along with the time constraint, left certain themes unaddressed for some participants. It might be worthwhile to replicate this study with a traditional interview format. Finally, the sample was limited in its generalizability as most of the participants were female, students and from the Washington, DC metropolitan area.

\subsection{Implications}

The current research may be useful for interventions for stopping invalidation. While it may be important to intervene with Biracial people to help them manage experiences of invalidation, it is also important to intervene with perpetrators of invalidation, so that they are educated on invalidation and its effects. For example, perpetrators, particularly those who invalidate for the purposes of humor, may not realize the effect that their invalidation is having on Biracial individual's cognitions, emotions and identity. People who perpetrate invalidation may be educated about Rockquemore et al.'s (2009) model, which differentiates between ascribed race and personal understanding of racial identity, and propounds that it is acceptable when these two do not correspond.

\subsection{Future Research}

Future research might uncover ways that Biracial people might strategically respond to experiences of invalidation in ways that preserve their well-being. Direct behaviors in response to invalidation, such as deflection or resistance, may be important to investigate. Similarly, identifying factors that mitigate and exacerbate invalidation may also be important in helping 
Biracial individuals cope with these experiences. Findings from the current study suggested that it might be helpful for Biracial individuals undergoing invalidation to find relationships where their racial identity is affirmed and also to develop a healthy sense of self-esteem to weather the assaults on their racial identity. Future research should investigate the mediating role these mitigating factors may play in the link between invalidation and mental health outcomes.

Also, the current study opened up a new thread of research for examining factors that might contribute to perpetrators' need to invalidate. It would be interesting for future research to investigate perpetrators' reasons for invalidation, from the perspective of the perpetrator. This might help inform interventions to prevent invalidation.

\subsection{Conclusion}

To conclude, this study advanced understanding regarding experiences of racial invalidation, reasons why perpetrators invalidate, thoughts and feelings in reaction to invalidation, and the effects of invalidation on identity. Findings highlighted the incorrect assumptions about race that fuel the racial invalidation of Biracial people and the negative consequences of invalidation. One participant posed the following question, "Why are you trying to categorize me and not just letting me be who I am?" It is hoped that this type of research will help promote a more positive milieu in which Biracial people will no longer be forced into categories by others, but rather recognized as how that they define themselves. 


\section{Acknowledgements}

Funding for this study was provided by the Michael Sullivan Diversity Scholarship and The Association of Black Psychologists Graduate Student Research Award. Funders were not involved in the conduction of the research. The authors express their appreciation to Young Hwa Kim, Jared Utley, Charlene Kim, and Angelica Eng for their assistance with data collection. 


\section{References}

Buckley, T. R., \& Carter, R. T. (2004). Biracial (Black/White) women: A qualitative study of racial attitudes and beliefs and implications for therapy. Women \& Therapy, 27, 45-64. doi:10.1300/J015v27n01_04

Brunsma, D. L., \& Rockquemore, K. A. (2001). The new color complex: Appearances and Biracial identity. Identity: An International Journal of Theory and Research, 3, 29-52.

Coleman, V. H., \& Carter, M. M. (2007). Biracial self-identification: Impact on trait anxiety, social anxiety, and depression. Journal of Theory and Research, 7, 103-114. doi: $10.1080 / 15283480701326018$

Collins, J. F. (2000). Biracial Japanese American identity: An evolving process. Cultural Diversity \& Ethnic Minority Psychology, 6, 115-133.

Cooley, C. H. (1902). Human nature and the social order. New York: Scribner's.

Cross, W. E. (1978). The Thomas and Cross model of psychological nigrescence: A review. The Journal of Black Psychology, 5, 13-31.

Edwards, L. (2008). Working With Multiracial clients in therapy: Bridging theory, research, and practice. Professional Psychology: Research and Practice, 39, 192-201.

Gillem, A. R., \& Thompson, C. A. (2004). Introduction: Biracial women in therapy: Between the rock of gender and the hard place of race. Women \& Therapy, 27, 1-18. doi: 0.1300/J015v27n01_01

Harris, C. A. \& Khanna, N. (2010). Black is, Black ain't: Biracials, middle-class Blacks, and the social construction of blackness. Sociological Spectrum. 30, 639-670.

Harris, D. R., Sim, J. J. (2002). Who is Biracial? Assessing the complexity of lived race. American Sociological Review, 67, 614-627. 
Herman, M. (2010). Do you see what I am? Observers' backgrounds affect their perceptions of Biracial faces. Social Psychology Quarterly, 73, 58-78. doi:10.1177/01902725103614

Herring, R. (1992). Biracial children: An increasing concern for elementary and middle school counselors. Elementary School Guidance and Counseling, 27, 123-131.

Ho, K., Sidanius, D. T., Levin, M. R., \& Banaji, M. R. (2011). Evidence for hypodescent and racial hierarchy in the perception of Biracial individuals. Journal of Personality and Social Psychology, 100, 492-506. doi: 10.1037/a0021562

Hoersting, R. C. \& Rae Jenkins, S. (2011). No place to call home: Cultural homelessness, selfesteem and cross-cultural identities. International Journal of Intercultural Relations, 35, 17-30. doi:10.1016/j.ijintrel.2010.11.005

Khanna, N. (2004). The role of reflected appraisals in racial identity: The case of Biracial Asians. Social Psychology Quarterly, 67, 115-131.

Khanna, N. (2010). "If you're half Black, you're just Black": Reflected appraisals and the persistence of the one-drop rule. The Sociological Quarterly, 51, 96-121. doi:10.1111/j.1533-8525.2009.01162.x

Khanna, N. (2011). Biracial in America: Forming and performing racial identity. Lanham, MD: Lexington Books.

Leverette, T. (2009). Speaking Up: Mixed Race Identity in Black Communities. Journal Of Black Studies, 39, 434-445.

Lou, E., Lalonde, R.N., \& Wilson, C. (2011). Examining a multidimensional framework of racial identity across different Biracial groups. Asian American Journal of Psychology, 2, 79-90. doi: $10.1037 / \mathrm{a} 0023658$ 
Miville, M. L., Constantine, M. G., Baysden, M. F., \& So-Lloyd, G. (2005). Chameleon changes: An exploration of racial identity themes of Biracial people. Journal of Counseling Psychology, 52, 507-516. doi: 10.1037/0022-0167.52.4.507

Nadal, K. L., Sriken, J., Davidoff, K. C., Wong, Y. \& McLean, K. (2013), Microaggressions within families: Experiences of Biracial people. Family Relations, 62, 190-201. doi: $10.1111 / \mathrm{j} .1741-3729.2012 .00752 . x$

Nakashima, C. L. (1992). An invisible monster: The creation and denial of mixed-race people in America. In M. P. P. Root (Ed.), Racially mixed people in America (pp. 162-178). Newbury Park, CA: Sage.

Navarrete, V., \& Jenkins, S. R., (2011). Cultural homelessness, multiminority status, ethnic identity development and self-esteem. International Journal of Intercultural Relations, 35, 791-804. doi:10.1016/j.ijintrel.2011.04.006

Poston, C. W. (1990). The biracial identity development model: A needed addition. Journal of Counseling and Development, 69, 152-155.

Remedios, J. D., \& Chasteen, A. L. (2013). Finally, someone who “gets" me! Biracial people value others' accuracy about their race. Cultural Diversity And Ethnic Minority Psychology, 19, 453-460. doi:10.1037/a0032249

Rockquemore, K. A. (2002). Negotiating the color line: The gendered process of racial identity construction among Black/White Biracials. Gender \& Society, 16, 485-503. doi: $10.1177 / 0891243202016004005$

Rockquemore, K. A., Brunsma, D. L. (2001). Beyond Black: Biracial identity in America. Thousand Oaks, CA: Sage. 
Rockquemore, K. A., \& Brunsma, D. L. (2002). Socially embedded identities: Theories, typologies, and processes of racial identity among Black/White Biracials. The Sociological Quarterly, 43, 335-356. doi: 10.1111/j.1533-8525.2002.tb00052.x

Rockquemore, K. A., Brunsma, D. L., \& Delgado, D. J. (2009). Racing to theory or retheorizing race? Understanding the struggle to build a Biracial identity theory. Journal of Social Issues. 65, 13-34. doi: 10.1111/j.1540-4560.2008.01585.x

Rockquemore, K. A., \& Laszloffy, T. A. (2003). Multiple realities: A relational narrative approach in therapy with Black-White mixed-race clients. Family Relations, 52, 119-128. doi: 10.1111/j.1741-3729.2003.00119.x

Romo, R. (2011). Between Black and Brown: Blaxican (Black-Mexican) Biracial identity in California. Journal of Black Studies, 42, 402-426. doi:10.1177/0021934710376172

Salahuddin, N. M., \& O’Brien, K. M. (2011). Challenges and resilience in the lives of urban, Biracial adults: An instrument development study. Journal of Counseling Psychology, 58, 494-507. doi: 10.1037/a0024633

Sanchez, D. T. (2010). How do forced-choice dilemmas affect Biracial people? The role of identity autonomy and public regard in depressive symptoms. Journal of Applied Social Psychology, 40, 1657-1677.

Shih, M., \& Sanchez, D. T. (2005). Perspectives and research on the positive and negative implications of having multiple racial identities. Psychological Bulletin, 131, 569-591. doi:10.1037/0033-2909.131.4.569

Shih, M., \& Sanchez, D. T. (2009). When race becomes even more complex: Toward understanding the landscape of Biracial identity and experiences. Journal of Social Issues, 65, 1-11. doi: 10.1111/j.1540-4560.2008.01584.x 
Stonequist, E. V. (1937). The marginal man: A study in personality and culture conflict. New York: Russell \& Russell.

Swann, W. B., Jr. (2012). Self-verification theory. In P. A. M. Van Lange, A. W. Kruglanski,. \& E. T. Higgins (Eds.), Handbook of theories of social psychology: Volume two (pp. 23-42), Thousand Oaks, CA: Sage.

Swann, W. B., Jr. \& Bosson, J. (2010). Self and identity. In S.T. Fiske, D. T. Gilbert, \& G. Lindzey (Eds.), Handbook of social psychology (5 ${ }^{\text {th }}$ ed; pp. 589-628), New York: McGraw-Hill.

Tashiro, C. J. (2002). Considering the significance of ancestry through the prism of mixed-race identity. Advances in Nursing Science, 25, 1-21.

Thompson, V. (2001). The complexity of African American racial identification. Journal Of Black Studies, 32(2), 155-165. doi:10.1177/002193470103200201

Townsend, S. S. M., Markus, H. R., \& Bergsieker, H. B. (2009). My choice, your categories: The denial of Biracial identities. Journal of Social Issues, 65, 185-204. doi:10.1111/j.15404560.2008.01594.x

Vivero, V. N., \& Jenkins, S. R. (1999). Existential hazards of the multicultural individual: Defining and understanding "cultural homelessness". Cultural Diversity \& Ethnic Minority Psychology, 5, 6-26. 
Table 1

Themes

\begin{tabular}{ll}
\hline Theme & Percentage (N) \\
\hline Reason for Invalidation Act & $59 \%(29)$ \\
Racial Stereotypes & $31 \%(15)$ \\
Appearance & $33 \%(16)$ \\
Ancestry & $35 \%(5)$ \\
Reasons for Perpetrator Invalidating & $41 \%(20)$ \\
Essentialist Views on Race & $18 \%(9)$ \\
Setting Someone Right & $12 \%(6)$ \\
Status Building/Personal Gain & $12 \%(6)$ \\
Humor & $10 \%(5)$ \\
Direct Behaviors in Response to Invalidation & $37 \%(18)$ \\
Resistance & $22 \%(11)$ \\
Deflecting & $16 \%(8)$ \\
Thoughts following Invalidation & $43 \%(21)$ \\
Internal Disagreement & $29 \%(14)$ \\
Reflections on How Others Construct Race & $22 \%(11)$ \\
Reflections on Race & $18 \%(9)$ \\
Feelings in Response to Invalidation & $69 \%(34)$ \\
Upset/Hurt & $33 \%(16)$ \\
Confusion & $20 \%(10)$ \\
Isolated & $20 \%(10)$ \\
Shocked/Surprised & $14 \%(7)$ \\
Uncomfortable & $12 \%(6)$ \\
Annoyed/Frustrated & $12 \%(6)$ \\
Angry & $12 \%(6)$ \\
Offended & $10 \%(5)$ \\
Effects of Invalidation on Racial Identity & $29 \%(14)$ \\
No Shift in Identity & $16 \%(8)$ \\
Shift in identity & $14 \%(7)$ \\
Factors that Exacerbate Invalidation & $20 \%(10)$ \\
Factors that Mitigate Invalidation & $20 \%(10)$ \\
&
\end{tabular}

